\title{
Evolution of the Monetary Transmission Mechanism in the US: The Role of Asset Returns
}

\author{
Beatrice D. Simo-Kengne \\ University of Pretoria \\ Pretoria, 0002 \\ SOUTH AFRICA \\ beatrice.simo_kengne@up.ac.za \\ Stephen M. Miller* \\ University of Nevada, Las Vegas \\ Las Vegas, Nevada, 89154-6005 \\ USA \\ stephen.miller@unlv.edu \\ and \\ Rangan Gupta \\ University of Pretoria \\ Pretoria, 0002 \\ SOUTH AFRICA \\ rangan.gupta@up.ac.za
}

\begin{abstract}
This paper investigates whether changes in the monetary transmission mechanism as captured by the interest rate respond to variations in asset returns. We distinguish between lowvolatility (bull) and high-volatility (bear) markets and employ a TVP-VAR approach with stochastic volatility to assess the evolution of the interest rate in relation to housing and stock returns. We measure the relative importance of housing and stock returns in the movements of the interest rate and their possible feedback effects over both time and horizon and across regimes. Empirical results from annual data on the US spanning the period from 1890 to 2012 indicate that the interest rate responds more strongly to asset returns during low-volatility (bull) regimes. While the bigger interest-rate effect of stock-return shocks occurs prior to the 1970s, the interest rate appears to respond more strongly to housing-return than stock return shocks after the 1970s. Similarly, a higher interest rate exerts a larger effect on both asset categories during lowvolatility (bull) markets. Particularly, larger negative responses of housing return to interest-rate shocks occur after the 1980s, corresponding to the low-volatility (bull) regime in the housing market. Conversely, the stock-return effect of interest-rate shocks dominates before the 1980s, where stock-market booms achieved more importance.
\end{abstract}

Keywords: $\quad$ Monetary policy, housing return, stock return, TVP-VAR

JEL classification: C32, E52, G10

* Corresponding author. 


\section{Introduction}

The early 1980s saw the beginning of the Great Moderation, when many macroeconomic variables exhibited decreased volatility. Debate followed about the causes of this moderation. Did it reflect good policy or good luck? The good-luck proponents argued that policy makers now understood how to moderate the business cycle. The Great Moderation also saw a general fall in inflation rates around the world. A leading explanation of the declining inflation rates relied on inflation targeting, which many central banks adopted over this time frame. Of course, the financial crisis and Great Recession shattered that optimistic view of the policy making process and the ability of policy makers to moderate business cycle movements. ${ }^{1}$

During the Great Moderation, however, asset prices became more volatile, leading eventually to the financial crisis and Great Recession. Borio et al., (1994) and Detken and Smets (2004) report the emergence of the boom-bust cycles in equity and housing prices across many developed countries during the 1980s. Further, Bernanke and Gertler (2004) argue that the increased asset-price volatility caught the attention of researchers and policy makers, especially since central bankers apparently now knew how to control inflation.

This study adopts a Time Varying Parameter Vector Autoregressive (TVP-VAR) approach beginning with a Markov Switching Autoregressive (MS-AR) model to assess the evolution of the monetary transmission mechanism as represented by the interest rate in relation to asset returns over the annual period of 1890 to 2012. Unlike previous studies, our approach measures the relationship between the two variables not only over different time and horizons

\footnotetext{
${ }^{1}$ For example, Kim and Nelson (1999), McConnell and Perez-Quiros (2000), Blanchard and Simon (2001), and Ahmed et al. (2004), among others, document a structural change in the volatility of U.S. GDP growth, finding a rather dramatic reduction in GDP volatility. Stock and Watson (2003), Bhar and Hamori (2003), Mills and Wang (2003), and Summers (2005) show a structural break in the volatility decline of the output growth rate for Japan and other G7 countries, although the break occurs at different times.
} 
but more importantly across different regimes. Our sample period covers several important changes that potentially affect the monetary transmission mechanism. First, the Federal Reserve did not exist prior to 1913. Second, the Great Depression led to significant regulatory change in the monetary sector as well as altered the Federal Reserve's understanding of its role in the economy. Finally, the post-WWII period saw the Great Inflation (1970s), the Great Moderation (1980s through mid-2000s), and the Great Recession (late-2000s). Thus, the TVP-VAR method can account for historical episodes of structural changes with time-varying effects on the VAR parameters.

A growing literature emphasizes the role of asset-price fluctuations in driving financial and business cycle dynamics (e.g., Bernanke and Gertler). First, asset-price variation potentially affects the real economy as a consequence of a direct effect on household wealth on consumption demand (e.g., Zhou and Carroll, 2012; Case et al. 2013; Liu et al., 2013; Guerrieri and Iacoviello, 2013; Mian et al., 2013). Second, the balance-sheet channel argues that credit markets include significant frictions, whereby those borrowers with strong financial credentials stand a better chance of obtaining a loan than borrowers with weak financial credentials. Additionally, forward-looking, rational economic agents incorporate the fluctuation in asset prices in their expectations (Gelain and Lansing, 2013), which, in turn, affects the propagation mechanism of shocks.

The emergence of inflation in asset prices caused a reappraisal of what monetary policy makers should or should not do when faced with rapid increases in asset prices. Bernanke and Gertler (2001) argue that policy makers do not need to respond to rising asset prices that reflect changing fundamentals in asset markets. Rather policy makers need to pay attention when asset prices rise because of non-fundamental factors and when asset-price changes cause important 
effects in the macroeocnomy. The ability of policy makers to identify the difference between fundamental and non-fundamental changes in asset prices proves most difficult. Thus, any policy that requires the central bank to diffuse asset-price inflation before it forms a bubble requires that the central bank identify bubble situations before and during their formation, no easy task

An additional problem faces monetary policy makers when faced with rising asset prices. Traditional monetary policy focuses on controlling inflation, typically measured by the consumer price index. But, this measure of inflation excludes asset-price inflation. How should policy makers respond to a situation of low consumer price inflation coupled with rapid inflation in equity and real estate prices?

Asset-price shocks precipitate reactions from the policy makers and, hence, modify the transmission mechanism of macroeconomic policies. Two related issues are of particular interest. How can monetary policy makers use asset-price shocks to improve its ability to pursue financial and macroeconomic stability? How does monetary policy affect asset prices? In fact, the recent global financial crisis and the subsequent Great Recession in the US, prompted by the crash of housing and stock markets, highlight the importance of these asset prices as instruments for the monetary authorities. These events renewed the interest of researchers and policy makers in the linkages between monetary policy and asset prices, particularly, housing and stock prices.

As noted above, developments in asset markets may respond to monetary policy while at the same time, fluctuations in asset prices likely affect the conduct of the monetary policy. Bordo and Wheelock (2004) discuss three different arguments for how asset-price bubbles develop. First, the traditional view argues that an asset-price boom results from the growth in the money supply. The excess liquidity causes asset prices to rise and, thus, transmits the monetary policy strategy to the entire economy. Second, Bordo and Wheelock refer to the Austrian or Bank of 
International Settlements (BIS) view, where rising asset prices can degenerate into a bubble situation when the policy makers do not intervene to control the expansion of credit. That is, the policy makers enter a situation where consumer price inflation remains benign while asset-price inflation enters a bubble. Third, researchers examine equilibrium rational expectations models that can generate asset-price bubbles when the monetary authorities do not commit to a stead long-run inflation rate.

Given the stability goal of modern economies, numerous studies assess the interplay between asset prices and the US monetary policy with contradicting results. One reason for disparate findings reflects the fact that monetary policy experienced dramatic evolution over the past decades. ${ }^{2}$ On the one hand, Bernanke and Gertler (2001) indicate that no need exists for monetary policy to react to asset-price fluctuations, except to the extent that they help forecasting inflation. Similarly, Filardo (2000) finds little evidence that the use of real estate and equity prices can improve the conduct of the monetary policy. Further, Gilchrist and Leahy (2002) argue strongly that asset prices should not enter monetary policy rules. Bordo and Wheelock (2004) find no consistent relationship between inflation and stock market booms. Indeed, they find that booms in asset prices are partly driven by fundamentals. Kohn (2009) relates that the Federal Open Market Committee (FOMC) frequently projects the future path of the economy based on different economic and policy assumptions including the evolution of asset prices.

On the other hand, other studies document an important role for asset prices as information variables for the monetary transmission mechanism. Goodhart and Hofmann (2001) show that useful information about future inflation comes from financial conditions indexes that

\footnotetext{
${ }^{2}$ Boivin (2005) identifies important changes in the monetary policy rules with a weak response to inflation in 1970s which gradually strengthened from the early 1980s. The evolution of the US monetary policy mechanism received confirmation by Koop et al. (2009) and Sims and Zha (2006).
} 
include property and stock prices. Mishkin (2001) supports this view and substantiates the important role of asset prices in the conduct of monetary policy. He notes, however, that targeting asset prices by central banks may worsen economic performance while eroding the central bank independence. More innovatively, Bordo and Jeanne (2002) argue that under certain circumstances, proactive monetary policy may diffuse asset-price booms. Accordingly, they show that in the event of a credit crunch, incorporating asset prices directly into the central bank objective function will probably prove more beneficial in terms of output gain than injecting liquidity ex post.

In the US literature, the few studies that implement the TVP-VAR methodology include Primiceri (2005), Koop et al. (2009), and Korobilis (2013). The common theme from these studies establishes evidence of changes in the monetary policy transmission in response to exogenous shocks. Our study relates to this recent empirical literature on monetary policy by focusing on specific asset-price shocks. The next section briefly presents the methodology. Section 3 describes the data. Section 4 discusses the empirical findings and section 5 concludes.

\section{Empirical methodology}

Primiceri (2005) developed the TVP-VAR model. Its flexibility and robustness capture the timevarying properties underlying the structure of the economy. More recently, Nakajima (2011) argues that the TVP-VAR model with constant volatility probably produces biased estimates due to the variation of the volatility in disturbances, thus emphasizing the role of stochastic volatility. The TVP-VAR model with stochastic volatility avoids this misspecification issue by accommodating the simultaneous relations among variables as well as the heteroskedasticity of the innovations. This gain in flexibility comes at the expense of a more complicated estimation 
structure. The estimation of the model requires using Markov-Chain Monte-Carlo (MCMC) methods with Bayesian inference.

The TVP-VAR model emerges from the basic structural VAR model defined as follows:

$$
A y_{t}=F_{1} y_{t-1}+\ldots+F_{s} y_{t-s}+u_{t}, \quad t=s+1, \ldots, n
$$

where $y_{t}$ denotes a $k \times 1$ vector of observed variables, and $A, F_{1}, \ldots, F_{s}$ denote $k \times k$ matrices of coefficients. The disturbance vector $u_{t}$ is a $k \times 1$ structural shock assumed to follow a normal distribution of the form $u_{t} \sim N(O, \Sigma)$, where

$$
\Sigma=\left(\begin{array}{cccc}
\sigma_{1} & 0 & \cdots & 0 \\
0 & \ddots & \ddots & \vdots \\
\vdots & \ddots & \ddots & 0 \\
0 & \cdots & 0 & \sigma_{k}
\end{array}\right)
$$

To specify the simultaneous relations of the structural shock by recursive identification, A takes on a lower-triangular structure as follows:,

$$
A=\left(\begin{array}{cccc}
1 & 0 & \cdots & 0 \\
a_{21} & \ddots & \ddots & \vdots \\
\vdots & \ddots & \ddots & 0 \\
a_{k 1} & \cdots & a_{k, k-1} & 1
\end{array}\right) .
$$

The model in equation (1) solves for the following reduced form specification:

$$
y_{t}=B_{1} y_{t-1}+\ldots+B_{s} y_{t-s}+A^{-1} \Sigma \varepsilon_{t}, \quad \varepsilon_{t} \sim N\left(0, I_{k}\right)
$$

where $B_{i}=A^{-1} F_{i}$ for $i=1, \ldots, s$. Stacking the elements in the rows of the $B_{i}^{\prime} s$ to form $\beta$ $\left(k^{2} s \times 1\right.$ vector $)$, and defining $X_{t}=I_{k} \otimes\left(y_{t-1}^{\prime}, \ldots, y_{t-s}^{\prime}\right)$, where $\otimes$ denotes the Kronecker product, we can rewrite the model as follows:

$$
y_{t}=X_{t} \beta+A^{-1} \Sigma \varepsilon_{t}
$$


By allowing the parameters in equation to change over time, we can rewrite the model in the following specification: ${ }^{3}$

$$
y_{t}=X_{t} \beta_{t}+A_{t}^{-1} \Sigma_{t} \varepsilon_{t}, \quad t=s+1, \ldots, n,
$$

where the coefficients $\beta_{t}$, and the parameters $A_{t}$ and $\Sigma_{t}$ are all time varying. To model the process for these time-varying parameters, Primiceri (2005) assumes the parameters in equation (6) follow random-walk processes. Let $a_{t}=\left(a_{21}, a_{31}, a_{32}, a_{41}, \ldots, a_{k, k-1}\right)^{\prime}$ denote a stacked vector of the lower-triangular elements in $A_{t}$ and $h_{t}=\left(h_{1 t}, \ldots, h_{k t}\right)^{\prime}$ with $h_{j t}=\log \sigma_{j t}^{2}$ for $j=1, \ldots, k$, $t=s+1, \ldots, n$. Thus,

$$
\begin{aligned}
& \beta_{t+1}=\beta_{t}+u_{\beta_{t}}, \\
& a_{t+1}=a_{t}+u_{a_{t}}, \\
& h_{t+1}=h_{t}+u_{h_{t}},
\end{aligned} \quad\left(\begin{array}{c}
\varepsilon_{t} \\
u_{\beta_{t}} \\
u_{a_{t}} \\
u_{h_{t}}
\end{array}\right) \sim N\left(0,\left(\begin{array}{cccc}
I & 0 & 0 & 0 \\
0 & \Sigma_{\beta_{t}} & 0 & 0 \\
0 & 0 & \Sigma_{a_{t}} & 0 \\
0 & 0 & 0 & \Sigma_{h_{t}}
\end{array}\right)\right)
$$

for $t=s+1, \ldots, n$, where $\beta_{s+1} \sim N\left(\mu_{\beta_{0}}, \Sigma_{\beta_{0}}\right), a_{s+1} \sim N\left(\mu_{a_{0}}, \Sigma_{\beta_{0}}\right)$ and $h_{s+1} \sim N\left(\mu_{h_{0}}, \Sigma_{h_{0}}\right)$.

This methodology exploits the salient feature of the VAR model with time-varying coefficients to estimate a three variable VAR model (interest rate, housing return, and equity return), focusing on the dynamics of interest-rate adjustments in relation with both housing- and equity-return adjustments. By allowing all parameters to vary over time, this paper examines the assumption of parameter constancy for the VAR's structural shocks based on the standard recursive identification procedure known as the Choleski decomposition. We achieve identification by imposing a lower triangular representation on the matrix $A_{t}$. The recursive

\footnotetext{
${ }^{3}$ See Nakajima (2011) and Pimiceri (2005) for further details on the TVP-VAR methodology.
} 
ordering of the variables that proves consistent with the VAR based empirical literature on monetary policy. That is, the interest rate comes first in the ordering and it does not respond contemporaneously to housing and equity-return shocks, while the housing return reacts with a lag to equity return shocks. Thus, the housing return appears third in the ordering after the equity (stock-market) return.

\section{Data}

To examine the time-varying effects of housing- and equity-return shocks on the monetary policy, we estimate the three-variable TVP-VAR model using annual data from 1890 to 2012. The dataset comes primarily from the Online Data section of Robert Shiller's website ${ }^{4}$ and includes the real stock market price (RSP), the real housing price (RHP), and the short term interest rate (R) commonly used as the monetary policy instrument. The data series on these variables, however, only run to 2009 on Robert Shiller's website. We update the data through 2012, using the definition of the variables and sources outlined in the data files of Robert Shiller. The interest-rate variable appears to be stationary in levels. We transform the two asset-price variables into their log-differenced (i.e., return) form to ensure stationarity, given the existence of unit root in their level forms. ${ }^{5}$ Further, for ease of comparison and interpretation, we standardize all variables using the standard deviation. We choose a lag length of one based on the Akaike information criteria applied to a stable constant parameter VAR. Since we convert the variables into their growth rates and use one lag, the effective sample of our analysis starts in 1893.

\footnotetext{
${ }^{4}$ http://www.econ.yale.edu/ shiller/data.htm.

${ }^{5}$ We use standard unit-root tests: Augmented-Dickey-Fuller (ADF)(1981), Phillips-Perron (PP)(1988), DickeyFuller with Generalised-Least-Squares-detrending (DF-GLS)(Elliott et al., 1996), and the Ng-Perron modified version of the PP (NP-MZt)(2001) tests to confirm that the log-levels of the asset-price variables under consideration follow an integrated process of order 1 or I(1) processes. The unit-root tests are available on request from the authors.
} 


\section{Estimation results}

Table 1 reports the posterior estimates computed using the MCMC algorithm based on keeping 100,000 draws after 10,000 burn-ins. ${ }^{6}$ We perform diagnostic tests for convergence and efficiency. The 95-percent credibility intervals include the estimates of the posterior means and the convergence diagnostic (CD) statistics developed by Geweke (1992). We cannot reject the null hypothesis of convergence to the posterior distribution at the conventional level of significance. In addition, we also observe low inefficiency factors, confirming the efficiency (see Figure 1) of the MCMC algorithm in replicating the posterior draws. These results indicate that all three set of parameters ( $\Sigma_{\beta_{t}}, \Sigma_{a_{t}}, \Sigma_{h_{t}}$ ), as described in equation (7), do change over time.

\subsection{Estimates of the stochastic volatility}

Besides the time varying structure of the parameters of interest $\left(\Sigma_{\beta_{t}}, \Sigma_{a_{t}}, \Sigma_{h_{t}}\right)$, the volatility of asset-return shocks seems to match the evolution of the interest rate. Figure 2 plots the posterior draws for each time series (top graphs) and the posterior estimates of the stochastic volatility (bottom graphs). The pattern depicted by the volatility of the interest-rate shocks seem compatible with the historical evolution of the US monetary policy, at least from the establishment of the Federal Reserves in 1914. For example, Lubik and Schorfheide (2004) argue that the appointment of Paul Volker in 1979 as Federal Reserve Chairman marked a watershed event for monetary policy. Before Volker, the Federal Reserve implemented a passive

\footnotetext{
${ }^{6}$ The MCMC method assesses the joint posterior distributions of the parameters of interest based on certain prior probability densities that are set in advance. This paper implements the code of Nakajima (2011) by assuming the following priors: $\Sigma_{\beta} \sim I W(25,0.01 I),\left(\Sigma_{a}\right)_{i}^{-2} \sim G(4,0.02),\left(\Sigma_{h}\right)_{i}^{-2} \sim G(4,0.02)$, where $\left(\Sigma_{a}\right)_{i}^{-2}$ and $\left(\Sigma_{h}\right)_{i}^{-2}$ are the $\mathrm{i}^{\text {th }}$ diagonal of elements of $\Sigma_{a}$ and $\Sigma_{h}$, respectively. IW and G denote the inverse Wishart and the Gamma distributions, respectively. We use flat priors to set initial values of time-varying parameters such that: $\mu_{\beta_{0}}=\mu_{a_{0}}=\mu_{h_{0}}=0$ and $\Sigma_{\beta_{0}}=\Sigma_{a_{0}}=\Sigma_{h_{0}}=10 \times I$.
} 
monetary policy. That changes in 1979 and policy became much more aggressive. In their new Keynesian monetary dynamic stochastic general equilibrium (DSGE) model, they discover that the DSGE model exhibited indeterminacy and determinancy before and after 1979, respectively. We observe that 1979 saw the peak in interest-rate volatility.

Meulendyke (1998) describes how US monetary policy evolved over time with various changes reflecting different monetary policy objectives and their subsequent instruments. More specifically, the low volatility observed prior to 1970s matches diverse monetary frameworks for which interest rates did not play as important a role. Initially designed to control money and credit through bank reserves coordination (1920s), the open market policy of the Federal Reserve became more objective in the 1930s with the primarily goal of easing financial conditions following the Great Depression prompted by the collapse of the stock market. During World War II, monetary policy accommodated the war effort by holding down the cost of its financing in 1940s. The passage of the Treasury-Federal Reserve Accord of 1952 released the Federal Reserve from the obligation of keeping the interest cost of the federal debt lower, which they did during World War II. The Federal Reserve adopted the "bills only" policy in the 1950s, which confined monetary policy to open markets operations in short maturity Treasury securities, bills, and certificates of indebtedness with discount rate and reserve requirement changes used as occasional supplements. Interestingly, the Federal Reserve adjusted margin requirements on stock purchase occasionally to boost or dampen credit use (Meulendyke, 1998), thus reflecting the observed increase in the volatility of the interest-rate shocks.

In the late 1970s, US monetary policy moved from funds rate targeting to targeting money and non-borrowed reserves (1979-1982) and subsequently to monetary and economic objectives with borrowed reserves targets. This finally makes interest rates the key instrument in 
the conduct of the US monetary policy, hence justifying the higher interest-rate volatility towards the end of the sample period. In relation to asset markets, the big increase in the volatility of the interest rate in early 1980s coincides with the boom period of the two asset prices and, therefore, the lowering of both asset-return volatilities. Though the relatively high volatility in both real housing and real equity returns, we observe some interesting differences with regards to the evolution of these two asset returns. The real housing return exhibits relative spikes between 1891 and 1951, although Shiller (2005) indicates the absence of any major real estate boom before 1940 and associates the observed decrease to World War I with the great influenza pandemic of 1918-19, the severe recession in 1920-21, and the high unemployment during the 1930s Great Depression. Between the 1940s and 1960s, while interest-rate volatility remains low, the real housing return exhibits a relative increase in volatility whereas the real equityreturn volatility shows a downward trend. After a long period of relative stability, the real housing return experiences new increases in volatility toward the end of the sample, coinciding with the recent housing boom, which began prior to the financial crisis and Great Recession in the late 2000s. In the second half of 2000s, where peaks in the housing market followed peaks in the stock market with an average lag of three years, we observe the same increase in asset-return and interest-rate volatility. This suggests the possibility of significant changes in the relationship between the interest rate and asset returns over time, hence providing the rationale for using a TVP-VAR where the sources of time variation include both the coefficients and the variance of the innovations.

Prior to World War II, monetary policy experienced three phases. The gold standard operated prior to World War I where housing-return volatility exceeded equity-return volatility and interest-rate volatility followed a downward trend into the war period. During World War I 
the newly charted Federal Reserve help to keep the interest cost of the federal debt low and we observe relatively low interest-rate volatility. After World War I, the world community tried to return to the gold standard, which did not succeed. In the interwar period, housing-return volatility declined while equity-return volatility rose reaching its peak in our sample during the Great Depression. In addition, the nominal interest rate falls to its lowest point during the Great Depression until the more recent financial crisis and Great Recession.

\subsection{Evolution of the monetary policy}

With the evidence of high volatilities in the dynamics of housing and equity returns, we also explore the possibility of regime switches in the two financial markets, which may bring out policy changes across regimes. We implement a Markov Switching Autoregressive (MS-AR) model estimated for each asset category, which allows the identification of periods of high and low volatility. The existing literature argues that high (low) volatility of asset prices leads to bear (bull) markets (French, Schwert, and Stambaugh, 1987; Campbell and Hentschel, 1992; Glosten, Jagannathan, and Runkle, 1993; Ang, Hodrick, Xing, Y., and Zhang, 2006). ${ }^{7}$ Figure 3 plots the smoothed probabilities for the bull market. ${ }^{8}$ Consistent with the 1998-2007 housing boom, the housing market appears to enter the low-volatility (bull) regime from 1960s to the second half of 2000s. Unlike the housing market, the low-volatility (bull) regimes in the stock market disseminate throughout the sample period. Moreover, the patterns reveal different episodes of equity price booms identified by Bordo and Wheelock (2004): the 1920s, 1930s, 1950s, 1960s, 1980s and 1990s.

\footnotetext{
${ }^{7}$ Intuitively, high volatility leads to need for a higher return, which the market can accomplish with a lower asset price. Ang, Hodrick, Xing, Y., and Zhan (2006) state "Periods of high volatility also tend to coincide with downward market movements (see French, Schwert, and Stambaugh (1987) and Campbell and Hentschel (1992))." (p. 259).

${ }^{8}$ Refer to the estimation results in Table 2 dealing with the identification of the bull and bear regimes in the housing and stock markets.
} 
In sum, the housing return exhibits one extended low-volatility (bull) period from the mid-1950s through the mid-2000s whereas the equity return exhibits a series of low-volatility (bull) episodes that spread across the entire sample period. The low housing-return volatility period achieved a probability of one for nearly its entire length. The equity return experience of low volatility never achieved a probability of one. Choosing low equity return volatility periods only for a probability of greater than 0.5, we identify 10 episodes, early-1900s, late-1910s, mid1920s, mid- and late-1930s, early-1950s, early-1960s, early-1970s, mid-1980s, and late-1990s.

Another method of evaluating the evolution of the monetary transmission mechanism considers the impulse response functions from the TVP-VAR model over selected horizons (we consider 1 to 6 years ahead) at all points in time. This approach adds a third dimension to the analysis, hence allowing the interpretation in terms of magnitude of the responses at each step and across regimes. We begin by estimating the constant VAR impulse responses as a benchmark, which capture the average levels of impulse response functions at all points in time over the sample period. Despite the initial positive, but insignificant, response of equity return to a positive interest-rate shock, which lasts less than a year, the average effect of the interest-rate shock on both asset returns appears negative and generally insignificant throughout the time horizon (See panel A of Figure 4). The direction of the effect corroborates the view in the monetary literature that an increase in the interest rate likely lowers asset prices. The initial negative response of the housing return to an interest-rate shock, however, does prove significant in year one and then becomes insignificant, but negative, while rising to nearly zero in the remaining forecast horizon. Moreover, in terms of magnitude, the housing-return effect dominates the equity-return effect of the interest-rate shock in the short run (one year), which contradicts the evidence from the TVP-VAR. 
Unlike the constant VAR model, panel B of Figure 4 reveals a price puzzle at some points in time with the positive response of the housing return across different horizons. This puzzle effect possibly emerges as a result of the lack of information contained in the parsimonious three variables VAR (Korobilis, 2013). More interestingly, the magnitude of the housing-return response to an interest-rate shock exceeds in absolute value the response of the equity return after 1980, which includes the boom period in the housing market. In absolute value, the response of the housing return to a one-standard-deviation change in the interest rate ranges between 1- to 6-percent compared to the response of the equity return, which lies between 0 - and 1-percent. This contrasts with the relatively larger response of the equity return to an interest-rate shock prior to 1980, where the magnitude ranges between 1- to 5-percent in absolute value against a 1- to 3-percent response of the housing return to a one-standard-deviation change in the interest rate.

On the other hand, the positive feedback effects from both asset-return shocks to the interest rate prove consistent with previous studies (e.g., Demary, 2010; Ncube and Ndou, 2011; Gupta et al., 2011; Peretti at al., 2012; Simo-Kengne et al., 2013) and indicate that the monetary authorities increase the interest rate as asset returns increase, giving a countercyclical response of monetary policy to asset returns. Results from the constant VAR model show that equity-return shocks exhibit the larger effect on the interest rate over the 6-year horizon (see panel A of Figure 5).

Panel B of Figure 5, however, shows that the interest rate responds more strongly to housing-return shocks during its low-volatility (bull) regime. That is, the housing-return effect exceeds the equity-return effect after the early-1970s when the housing market experienced a low-volatility (bull) regime. During that period, the magnitude of the housing-return effect 
oscillates between 10- to 20-percent across horizons while a one-standard-deviation change in the equity return falls between 0 - to 10 -percent. Similarly, the response of the interest rate to an equity-return shock appears stronger across horizons in the early part of the sample, where stock market episodes of low volatility (booms) saw more prominence. Prior to 1970, a positive shock to the equity return leads to a 5- to 30- percent increase in interest rate at all horizons against a positive response to a housing-return shock ranging between 0 - to 10 - percent.

\section{Conclusion}

The evolution of the US monetary policy experienced numerous modifications and adjustments in response to various exogenous shocks of different sources. This paper evaluates a long dataset, covering annual observations over the period of 1890-2012, to characterize the dynamic relationship between asset returns and US monetary transmission, as captured by the nominal interest rate, based on a stochastic TVP-VAR approach and distinguishes between low- and highvolatility regimes to allow for more detailed interpretations. Moreover, we supplement the TVPVAR approach with a MS-AR model to identify switches between high- and low-volatility regimes.

The empirical results substantiate a larger response of the interest rate to asset-return shocks during low-volatility (bull) regimes, which correspond to a larger effect of interest-rate shocks on asset returns during boom periods. More specifically, interest-rate shocks exert a larger effect on the housing return than the equity return after 1980 that corresponds to the lowvolatility (bull) regime in the housing market. A higher response of the equity return to interestrate shocks occurs prior to1980.

We also find feedback effects of asset-return shocks onto the interest rate. The interest rate responds positively and more strongly to housing- than equity-return shocks after the early- 
1970s, while the interest rate responds more strongly to equity-return shocks prior to early1970s, where stock market booms exhibited more prominence. Our findings support an important role for asset returns in the conduct of the monetary policy.

We explored the possibility of regime switches between low- and high-volatility markets, using a Markov Switching Autoregressive (MS-AR) model estimated for each asset category. We identify periods of high volatility (bear markets) and low volatility (bull markets). The housing market experiences an extended and continuous low-volatility (bull) regime from the 1960s to the second half of the 2000s. Unlike the housing market, the low-volatility (bull) regimes in the stock market appear throughout the sample period for relatively short periods of time.

Finally, our results indicate that the 1970s featured a dramatic change in the relationships between asset returns and the interest rate. Chairman Volker took the leadership of the Federal Reserve Board of Governors in 1979 as the macroeconomy transitioned from the Great Inflation to the Great Moderation. The proponents of the good policy explanation of the Great Moderation view Volker's appointment as critical. That is, our findings support the view of Lubik and Schorfheide (2004), who argue that the Volker's appointment marked a watershed event for monetary policy. Before Volker, the Federal Reserve implemented a passive monetary policy in their view. 


\section{References:}

Ahmed, S., Levin, A., and Wilson, B. A., 2004. Recent U.S. macroeconomic stability: Good policies, good practices, or good luck? Review of Economics and Statistics 86, 824-832.

Ang, A., Hodrick, R. J., Xing, Y., and Zhang, X., 2006. The cross-section of volatility and expected returns. Journal of Finance 61, 259-299.

Aoki, K., Proudman, J., and Vlieghe, G., 2004. House prices, consumption and monetary policy: a financial accelerator approach. Journal of Financial Intermediation 13, 414-435.

Bernanke, B., and Gertler, M., 2001. Monetary policy and asset prices volatility. NBER working paper 7559, Cambridge.

Bhar, R., and Hamori, S., 2003. Alternative characterization of the volatility in the growth rate of real GDP. Japan and the World Economy 15, 223-231.

Blanchard, O., and Simon, J., 2001. The long and large decline in U.S. output volatility. Brookings Papers on Economic Activity 32, 135-174.

Boivin, J. 2005. Has US monetary policy changed? Evidence from drifting coefficients and realtime data. NBER working paper 11314, Cambridge.

Bordo, M.D., Dueker, M.J. and Wheelock, D.C. 2003. Aggregate price shocks and financial stability: The United Kingdom 1796-1999. Explorations in Economic History, 40(4), 143-69.

Bordo, M. D., Dueker, M. J. and Wheelock, D. C. 2002. Aggregate price shocks and financial stability: A historical analysis. Economic Inquiry, 40(4), 521-38.

Bordo, M.D. and Wheelock, D.C. 2004. Monetary policy and asset prices: A look back at past US stock market booms. NBER working paper 10704, Cambridge.

Bordo, M.D. and Jeanne, O. 2002. Monetary policy and asset prices: Does benign neglect make sense? International Finance, 5(2), 139-164.

Borio, C. E. V., Kennedy, N., and Prowse, S. D., 1994. Exploring aggregate asset price fluctuations across countries: Measurement, determinants, and monetary policy implications. Bank for International Settlements, BIS Economics Papers no. 40.

Campbell, J. Y., and Hentschel, L., 1992. No news is good news: An asymmetric model of changing volatility in stock returns. Journal of Financial Economics 31, 281-318.

Case, K., Quigley, J., and Shiller, R., 2013. Wealth effects revisited: 1975-2012. NBER Working Paper No. 18667. 
Demary, M. 2010. The interplay between output, inflation, interest rates and house prices. International evidence Journal of Property Research, 27(1),1-17.

Detken, C., and Smets, F., 2003. Asset price booms and monetary policy. manuscript, June.

Dickey, D. and Fuller, W. 1981. Likelihood ratio statistics for autoregressive time series with a unit root. Econometrica, 49, 1057-1072.

Elliott, G., Rothenberg, T.J. and Stock, J.H. 1996. Efficient tests for an autoregressive unit root. Econometrica, 64 (4), 813-836.

Filardo, A.J. 2000. Monetary policy and asset prices. Federal Reserve Bank of Kansas City Economic Review, Third Quarter, 11-37.

French, K. R., Schwert, G. W., and Stambaugh, R. F., 1987. Expected stock returns and volatility. Journal of Financial Economics 19, 3-29.

Gelain, P. and Lansing, K.J. 2013. House prices, expectations and time-varying fundamentals. Federal Reserve Bank of San Francisco Working Paper 2013-03.

Geweke, J., 1992. Evaluating the accuracy of sampling-based approaches to the calculation of posterior moments. In Bernado, J. M., Berger, J. O., Dawid, A. P., and Smith, A. F. M., (eds), Bayesian Statistics. 4, 169-188, New York: Oxford University Press.

Gilchrist, S. and Leahy, J.V. 2002. Monetary policy and asset prices. Journal of Monetary Economics, 49, 75-97.

Glosten, L. R., Jagannathan, R., and Runkle, D. E., 1993. On the relation between the expected value and the volatility of the nominal excess return on stocks. Journal of Finance 48, 1779-1801.

Goodhart, C. and Hofmann, B. 2001. Asset prices, financial conditions and the transmission of monetary policy. Conference on Asset Prices, Exchange Rates, and Monetary Policy, Stanford University, March 2-3, 2001.

Green, G. D., 1971. The economic impact of the stock market boom and crash of 1929. In Federal Reserve Bank of Boston, Consumer Spending and Monetary Policy: The Linkages, Monetary Conference, 189-220.

Guerrieri, L., and Iacoviello, M., 2013. Collateral constraints and macroeconomic asymmetries. Mimeo, Boston College.

Gupta, R., Jurgilas, M., Miller, S.M. and van Wyk, D. 2012. Financial market liberalization, monetary policy and housing sector dynamics. International Business and Economics Research Journal, 11(1), 69-82. 
Kim, C. J. and Nelson, C. R. (1999) Has the U.S. economy become more stable? A Bayesian approach based on a Markov-Switching model of the business cycle, Review of Economics and Statistics 81, 1-10.

Kohn, D.L. 2009. Monetary policy and asset prices revisited. Cato Journal, 29(1), 31-44.

Koop, G., Leon-Gonzalez, R. and Strachan, R.W. 2009. On the evolution of the monetary policy transmission mechanism. Journal of Economic Dynamics and Control, 33, 997-1017.

Korobilis, D. 2013. Assessing the transmission of monetary policy using time-varying parameter dynamic factor models. Oxford Bulletin of Economics and Statistics, 75(2), 157-179.

Liu, Z., Wang, P., and Zha, T., 2013. Land-price dynamics and macroeconomic fluctuations. Econometrica, 81, 1147-1184.

Lubik, T.A. and Schorfheide, F. 2004. Testing for indeterminacy: An application to US monetary policy. The American Economic Review, 94(1), 190-217.

McConnell, M. M., and Perez-Quiros, G., 2000. Output fluctuations in the United States: What has changed since the early 1980’s? American Economic Review 90, 1464-1476.

Meulendyke, A. M., 1998. US monetary policy and financial markets. Federal Reserve Bank of New York.

Mian, A. R., Rao, K., and Sufi, A., 2013. Household balance sheets, consumption, and the economic slump. Chicago Booth Research Paper no. 13-42, Fama-Miller Working Paper.

Mills, T. C., and Wang, P., 2003. Have output growth rates stabilized? Evidence from the G-7 economies. Scottish Journal of Political Economy 50, 232-246.

Mishkin, F. S., 2001. The transmission mechanism and the role of asset prices in monetary policy. NBER working paper 8617,Cambridge.

Mishkin, F. S., 2007. Housing and the Monetary Transmission Mechanism. Working Paper, Finance and Economic Discussion Series, Federal Reserve Board.

Nakajima, J., 2011. Time-varying parameter VAR model with stochastic volatility: An overview of methodology and empirical applications. Monetary and Economic Studies, 107-142.

Ncube, M. and Ndou, E. 2011. Monetary policy transmission, house prices and consumer spending in South Africa: An SVAR approach. Working Paper 133, African Development Bank.

Peretti, V., Gupta, R. and Inglesi-Lotz, R.2012. Do house prices impact consumption and interest rate in South Africa? Evidence from a Time Varying Vector Autoregressive model. Economics, Financial Markets and Management, 4, 101-120. 
Phillips, P., and Perron, P., 1988. Testing for a unit root in time series regression. Biometrika 75, 335-346.

Primiceri, G. E., 2005. Time varying structural vector autoregressions and monetary policy. Review of Economic Studies 72, 821-852.

Ng, S., and Perron, P., 2001. Lag lenth selection and the construction of unit root tests with good size and power. Econometrica 69, 1519-1554.

Shiller, R. J., 2005. Irrational exuberance. Princeton University Press, Princeton, New Jersey.

Simo-Kengne, B.D., Balcilar, M., Gupta, R., Aye, G.C. and Reid, M. 2013. Is the relationship between monetary policy and house prices asymmetric across bull and bear markets in South Africa? Evidence from a Markov-Switching Vector Autoregressive model. Economic Modelling, 32(1),161-171.

Sims, C.A. and Zha, T. 2006. Were regime switches in US monetary policy? The American Economic Review, 96(1), 54-81.

Stock, J. H., and Watson, M. W., 2003. Has the business cycle changed? Evidence and explanations, Monetary Policy and Uncertainty: Adapting to a Changing Economy. Proceedings of symposium sponsored by Federal Reserve Bank of Kansas City, Jackson Hole, Wyo., 9-56.

Summers, P. M., 2005. What caused the Great Moderation? Some cross-country evidence. Economic Review (Third Quarter), Federal Reserve Bank of Kansas City, 5-32.

Zhou, X., And Carroll, C. D., 2012. Dynamics of wealth and consumption: new and improved measures for U.S. states. The B.E. Journal of Macroeconomics, 12, 1-44. 


\section{Table 1: $\quad$ Posterior estimates results}

\begin{tabular}{lrrrcc}
\hline Parameters & Mean & \multicolumn{1}{c}{ Std Dev. } & 95\% Intervals & Geweke CD & Inefficiency \\
\hline$\left(\Sigma_{\boldsymbol{\beta}}\right)_{\mathbf{1}}$ & 0.0367 & 0.0066 & {$[0.0257,0.0516]$} & 0.514 & 11.62 \\
$\left(\boldsymbol{\Sigma}_{\boldsymbol{\beta}}\right)_{\mathbf{2}}$ & 0.0307 & 0.0051 & {$[0.0223,0.0423]$} & 0.381 & 8.83 \\
$\left(\boldsymbol{\Sigma}_{\boldsymbol{a}}\right)_{\mathbf{1}}$ & 0.0860 & 0.0312 & {$[0.0442,0.1623]$} & 0.152 & 48.19 \\
$\left(\boldsymbol{\Sigma}_{\boldsymbol{a}}\right)_{\mathbf{2}}$ & 0.0770 & 0.0299 & {$[0.0405,0.1525]$} & 0.850 & 57.57 \\
$\left(\Sigma_{\boldsymbol{h}}\right)_{\mathbf{1}}$ & 0.5293 & 0.1284 & {$[0.3071,0.8089]$} & 0.579 & 37.85 \\
$\left(\Sigma_{\boldsymbol{h}}\right)_{\mathbf{2}}$ & 0.4488 & 0.1069 & {$[0.2639,0.6826]$} & 0.372 & 30.18 \\
\hline
\end{tabular}

Note: The estimates of $\Sigma_{\beta}$ and $\Sigma_{a}$ are multiplied by 100 . 
Table 2: $\quad$ MS-AR estimates results

\begin{tabular}{ccc}
\hline & $\begin{array}{c}\text { Real House Prices (RHP) } \\
\text { (MS-AR(3)) }\end{array}$ & $\begin{array}{c}\text { Real Stock Prices (RSP) } \\
\text { (MS-AR(2)) }\end{array}$ \\
\hline Regime Dependent Intercept & -0.0423 & 0.0637 \\
$\mu_{1}$ & 0.0549 & $0.6838^{* * *}$ \\
$\mu_{2}$ & $0.1855^{* *}$ & -0.0039 \\
Standard Errors & $-1.2474^{* * *}$ & $-3.2795^{* * *}$ \\
$\sigma_{1}$ & & \\
$\sigma_{2}$ & 0.0081 & 0.0542 \\
Regime 1: Parameter estimates & 0.0295 & $-0.2486^{* *}$ \\
$\beta_{1,1}$ & -0.1654 & \\
$\beta_{1,2}$ & & $0.1911^{* * *}$ \\
$\beta_{1,3}$ & $1.0263^{* * *}$ & $0.3305^{* * *}$ \\
$\beta_{2,1}$ & -0.1703 & \\
$\beta_{2,2}$ & -0.1655 & -159.67 \\
$\beta_{2,3}$ & & 2.8279 \\
Fitting & -127.699 & 2.9222 \\
Log likelihood & 2.3479 & \\
AIC & 2.46217 & 0.9153 \\
HQ & & 0.1845 \\
Begime 2: Pameter estimates & 0.9873 & 11.8088 \\
Bull & 0.9712 & 1.2263 \\
\hline Expected Durations & 78.9628 & \\
Bear & 34.674 & \\
Bull & & \\
\hline \hline
\end{tabular}

Notes: Across the two asset markets, prices are more volatile in regime 1 than in regime 2 and the intercept is also lower in regime 1 than regime 2. Thus, regime 1 is identified as a bear market and regime 2 corresponds to a bull market. ${ }^{*},{ }^{* *}$ and ${ }^{* * *}$ indicate significance at the $10 \%$, $5 \%$ and $1 \%$ level of significance, respectively. 
Figure 1: Estimates of the moments and posterior distributions of the model
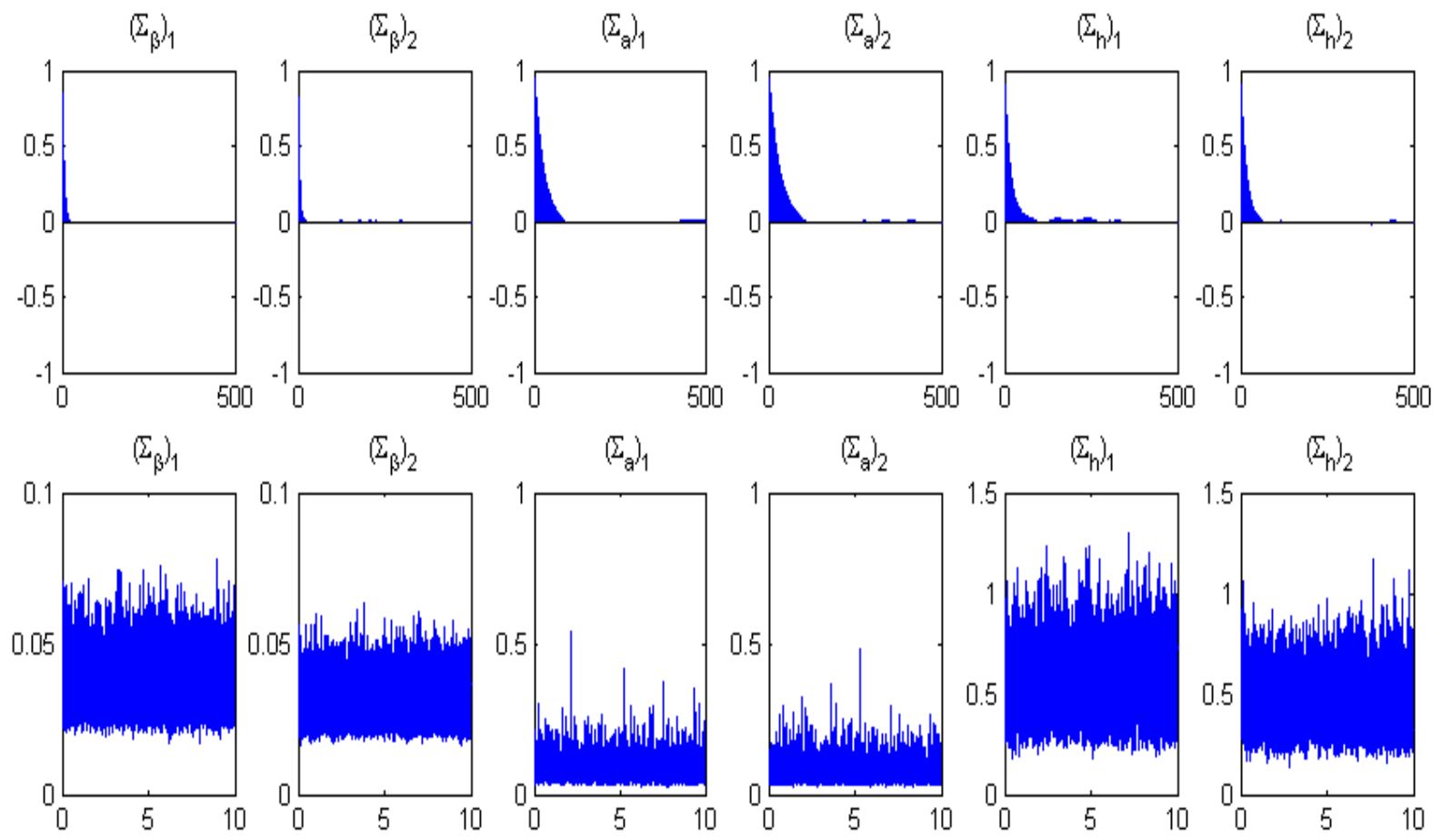

$\left(\Sigma_{\beta}\right)_{2}$

$\left(\Sigma_{\alpha_{1}}\right.$
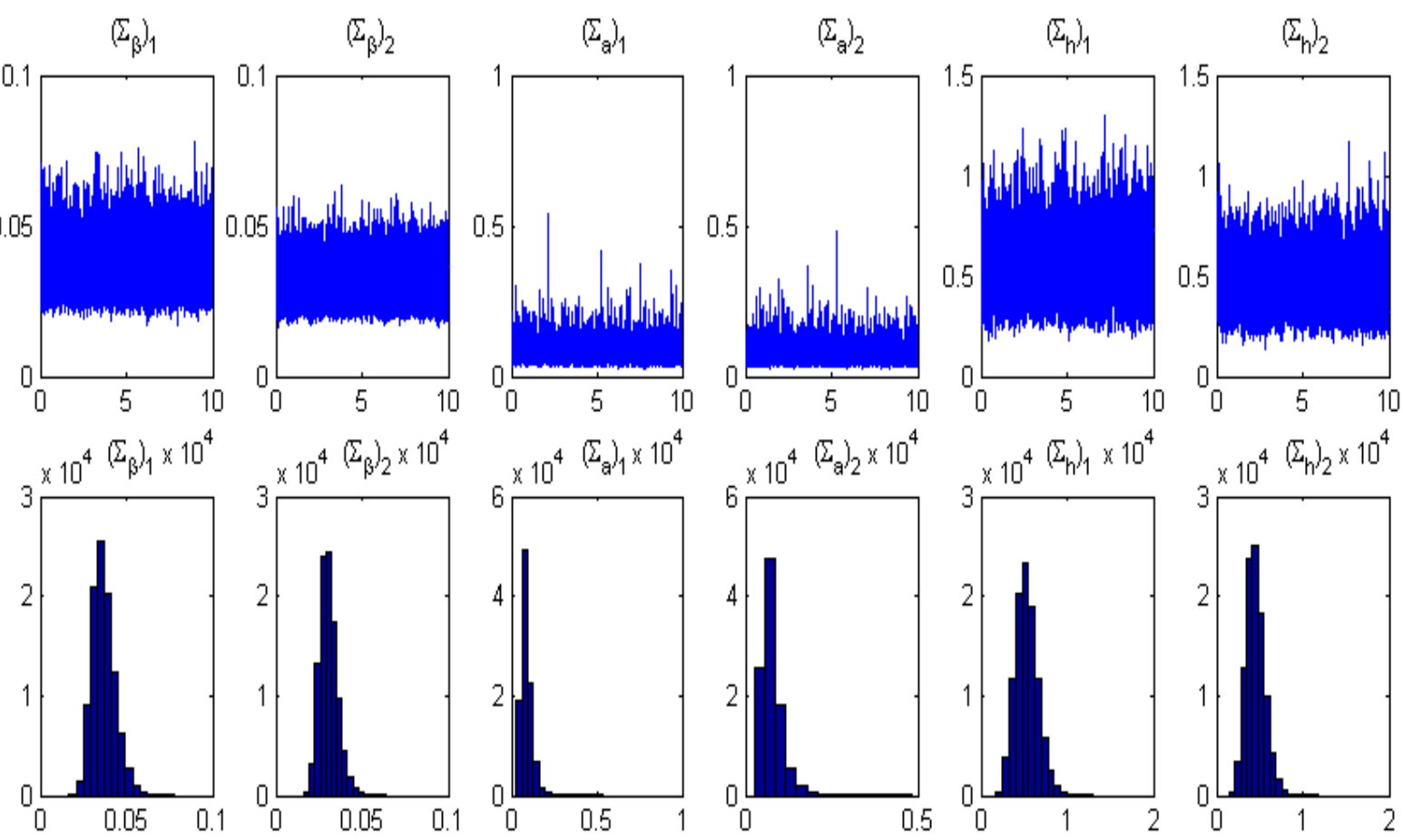

Note: Sample autocorrelations (Top chart), sample paths (middle chart), and posterior densities (bottom chart). The estimate of $\Sigma_{\beta}$ and $\Sigma_{a}$ are multiplied by 100 . 
Figure 2: Posterior estimates for the stochastic volatility of the structural shock
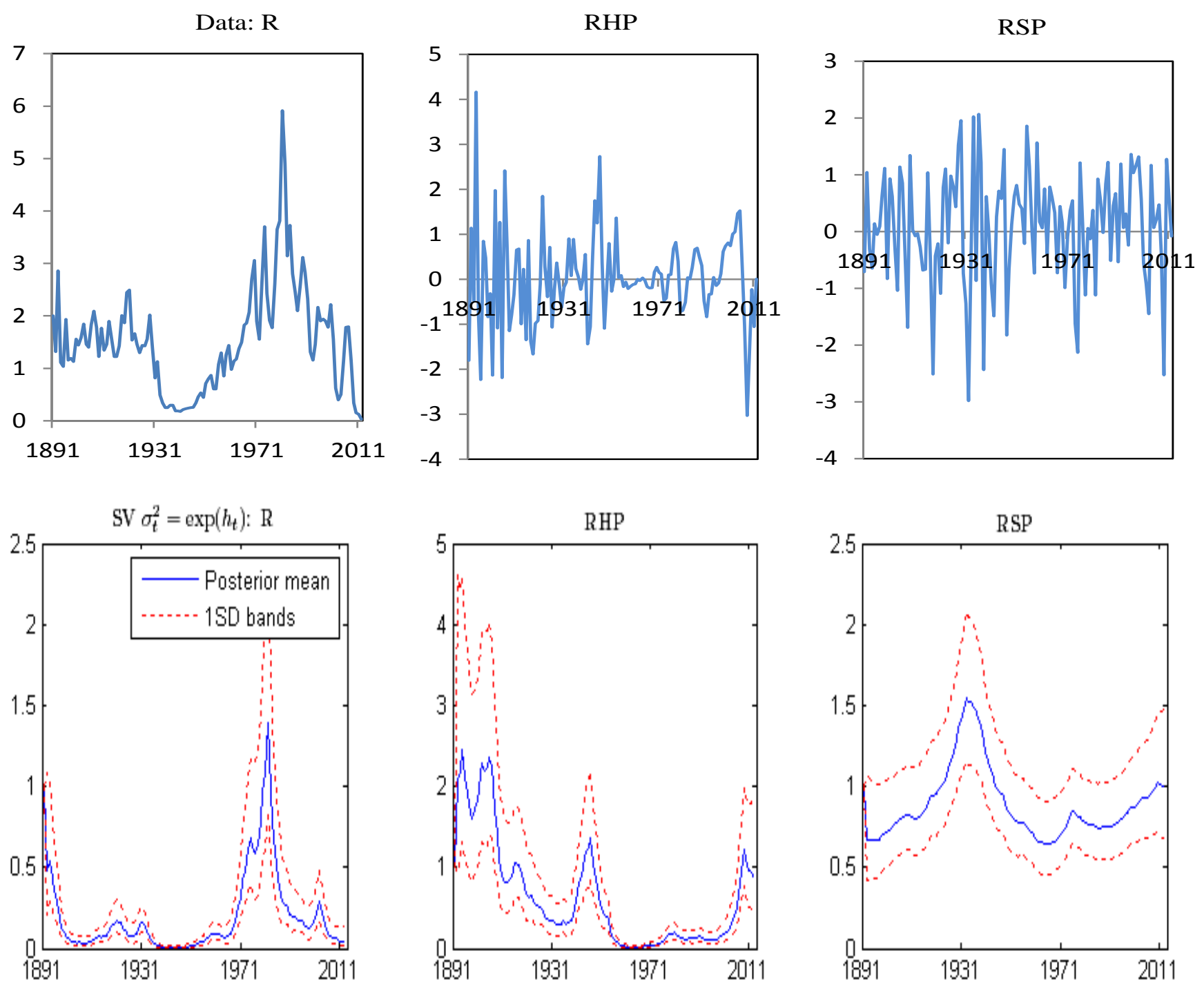
Figure 3: Smooth probabilities of bull market for stock and house prices
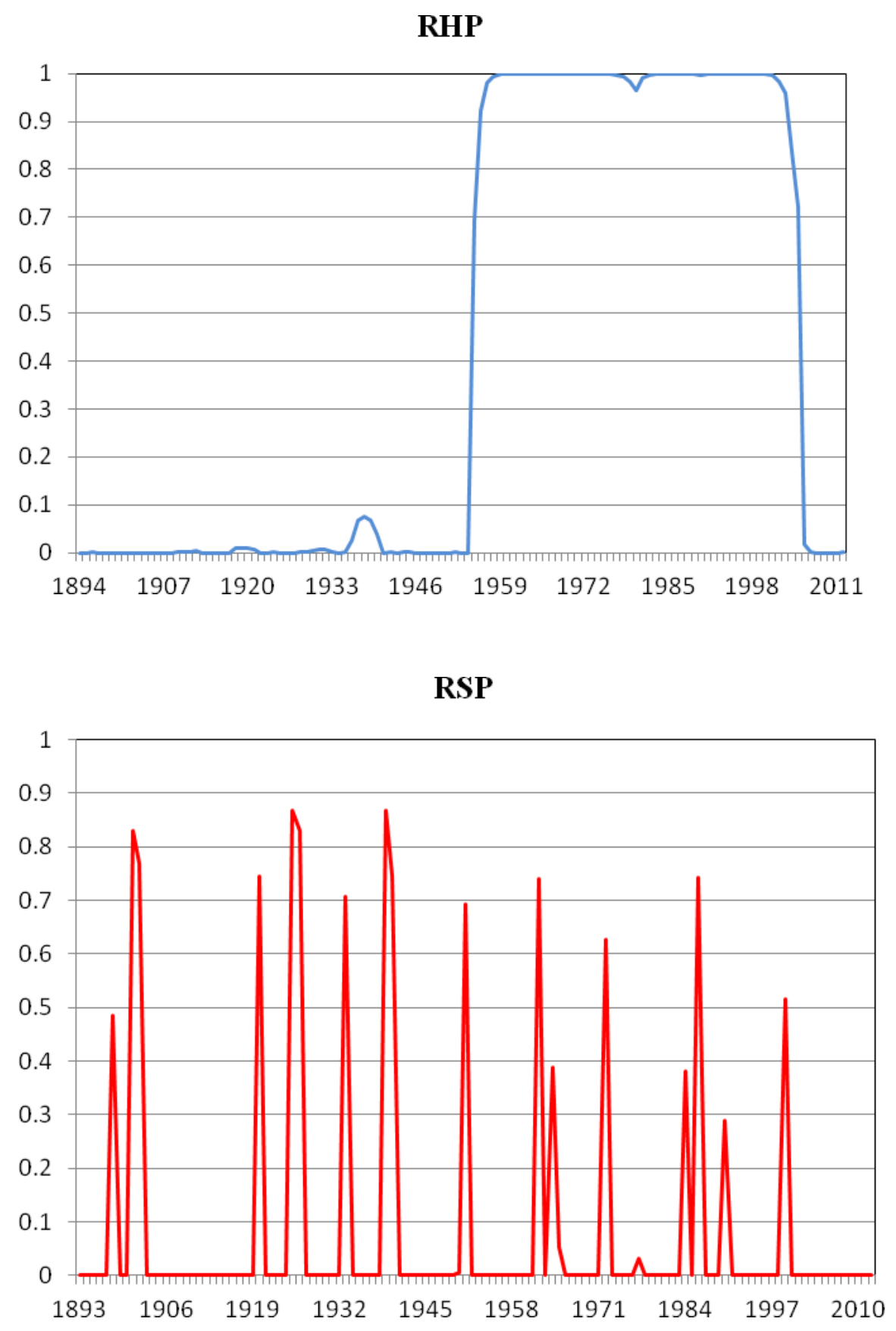
Figure 4: Impulse responses of house and stock prices to monetary policy shock A: Constant VAR model

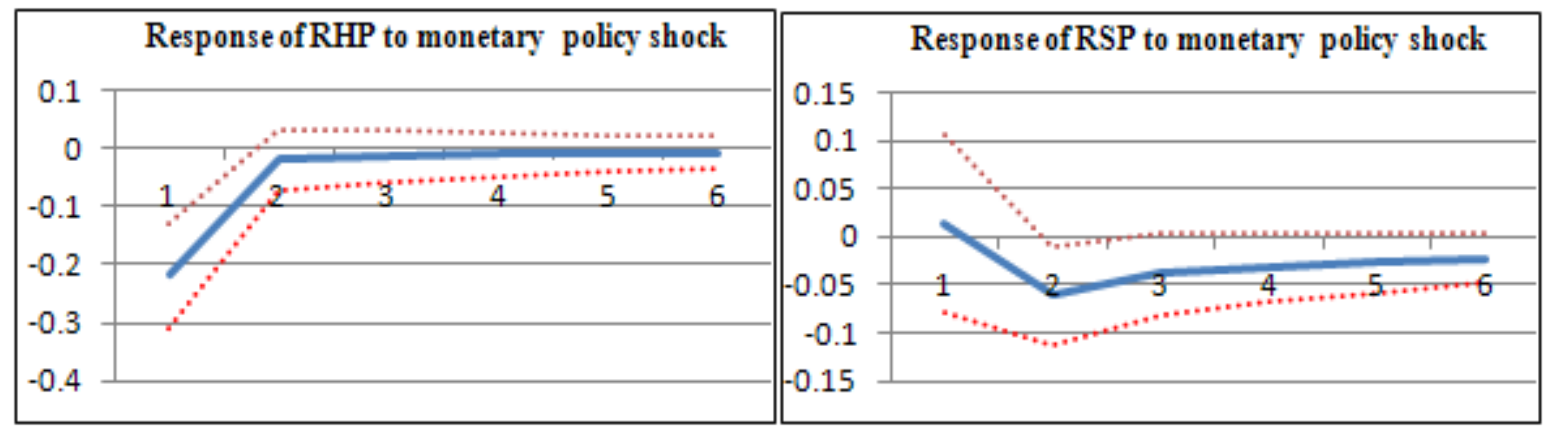

B: TVP-VAR model

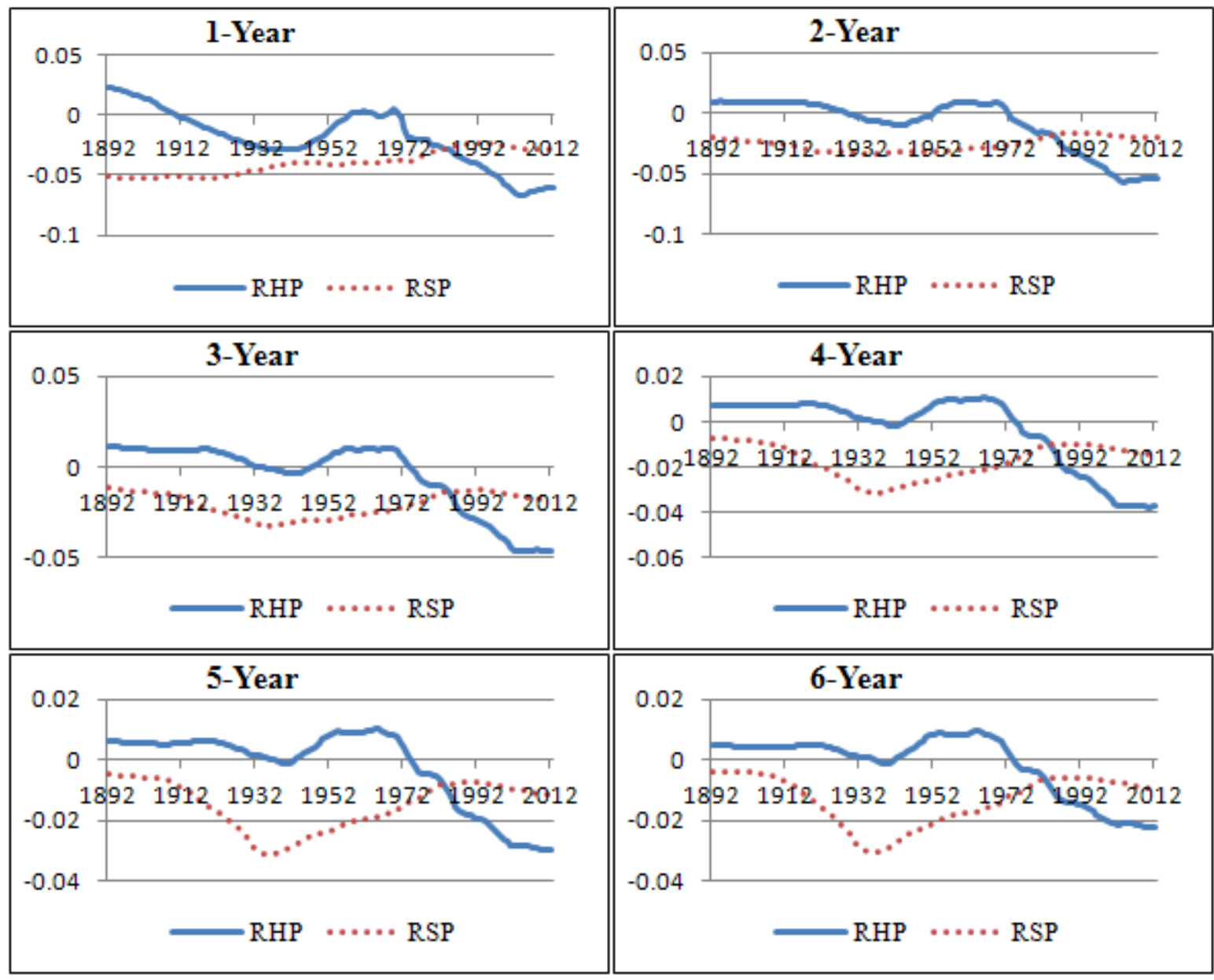


Figure 5: Impulse responses of monetary policy to house and stock prices shocks

\section{A: Constant VAR model}

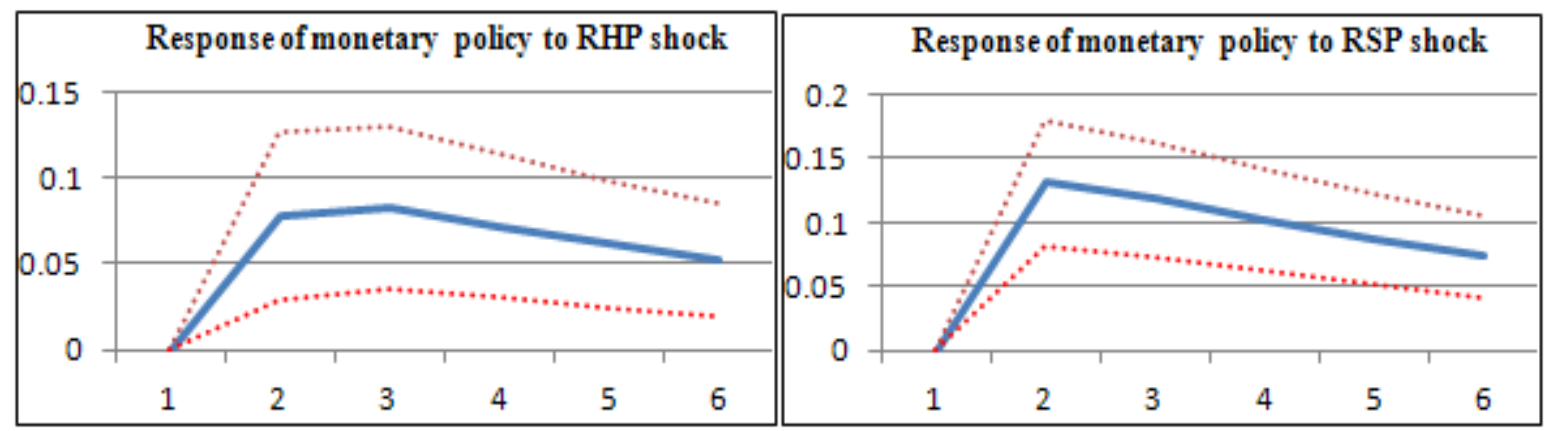

\section{B: TVP-VAR model}

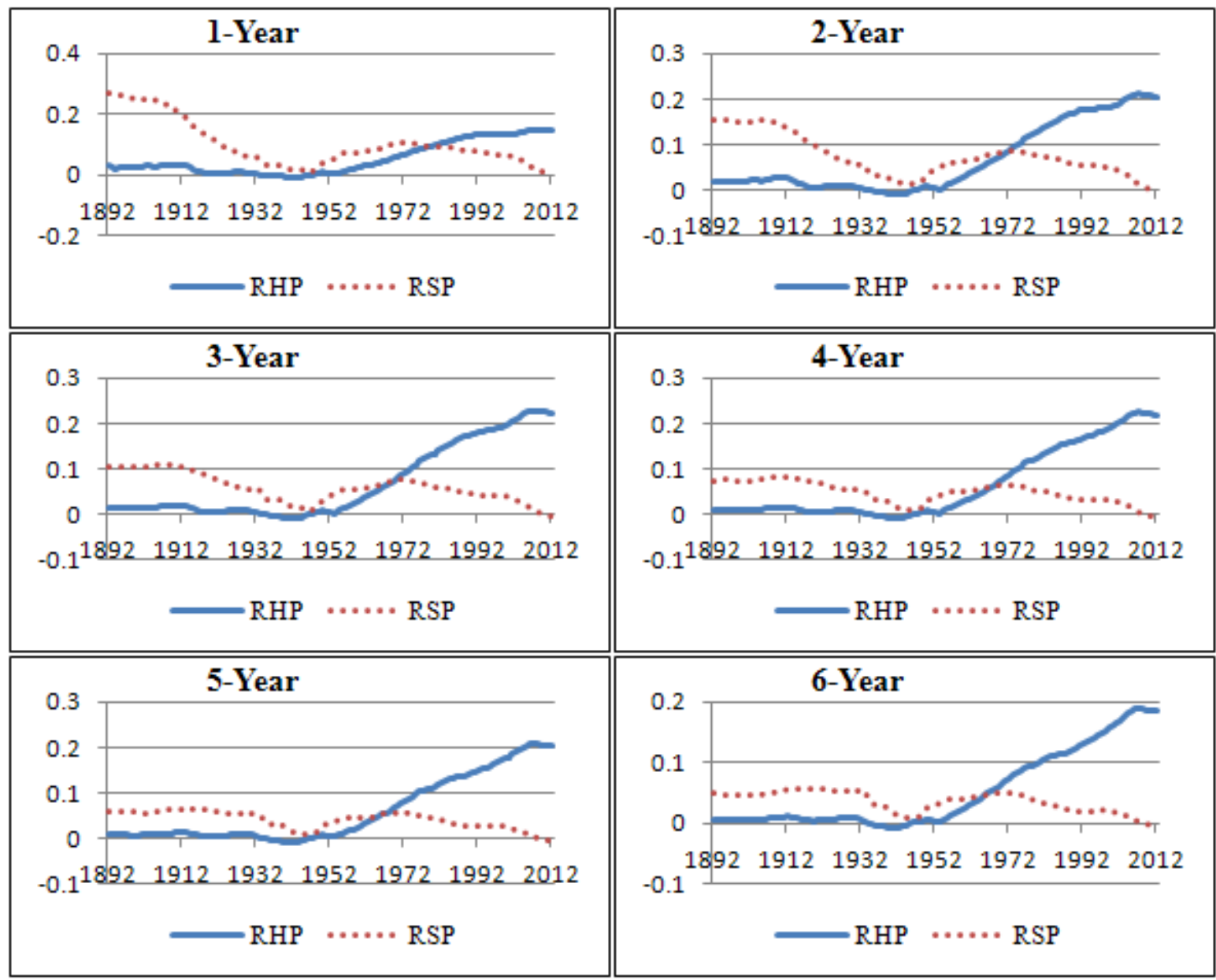

